"Mircea cel Batran" Naval Academy Scientific Bulletin, Volume XIX - 2016 - Issue 1

Published by "Mircea cel Batran" Naval Academy Press, Constanta, Romania // The journal is indexed in:

PROQUEST / DOAJ / DRJI / JOURNAL INDEX / I2OR / SCIENCE LIBRARY INDEX / Google Scholar / Crossref /

Academic Keys / ROAD Open Access / OAJI / Academic Resources / Scientific Indexing Services / SCIPIO

\title{
THE INFLUENCE OF FINISHING PARAMETERS OF ANTI-FRICTION LAYERS BY FINPLAST ON BEHAVIOR AT THE IMPACT
}

\section{Dumitru DASCALU}

Associate Prof. Ph.D., " Mircea cel Batran" Naval Academy, Constanta, Romania

Abstract: FINPLAST is original proceedings propose for finishing antifriction surfaces of sledding bearings. FINPLAST is an original method proposed for anti-friction surface finish of the sliding bearings. The process extends cold plastic deformation technology, for finishing antifriction surfaces of the sliding bearings. In this paper presents the results of the evaluation of the state of stresses and strains obtained by simulation using the finite element method.

Key words: FINPLAST, finishing, antifriction, surfaces, cold plastic deformation.

\section{Description of the process and technological parameters used \\ The process description}

The primary finish method by plastic deformation at cold named FINPLAST is described in the $1^{\text {st }}$ Figure. After splintering processing, the obtained surfaced shows on the depth a layer with different characteristic structural changes named layer influenced by splintering shortened to SIA. On surface plan are obtained geometrical deviations in the form of roughness, undulations etc. The finishing restricted possibilities of antifriction surfaces made the process proposed by author necessary. The originality of the process consists on the fact that the contact surface, of anti-friction material of the tribologycal couplings with sliding, previously obtained through splintering method, is subject on this finishing method by plastic deformation at cold FINPLAST.

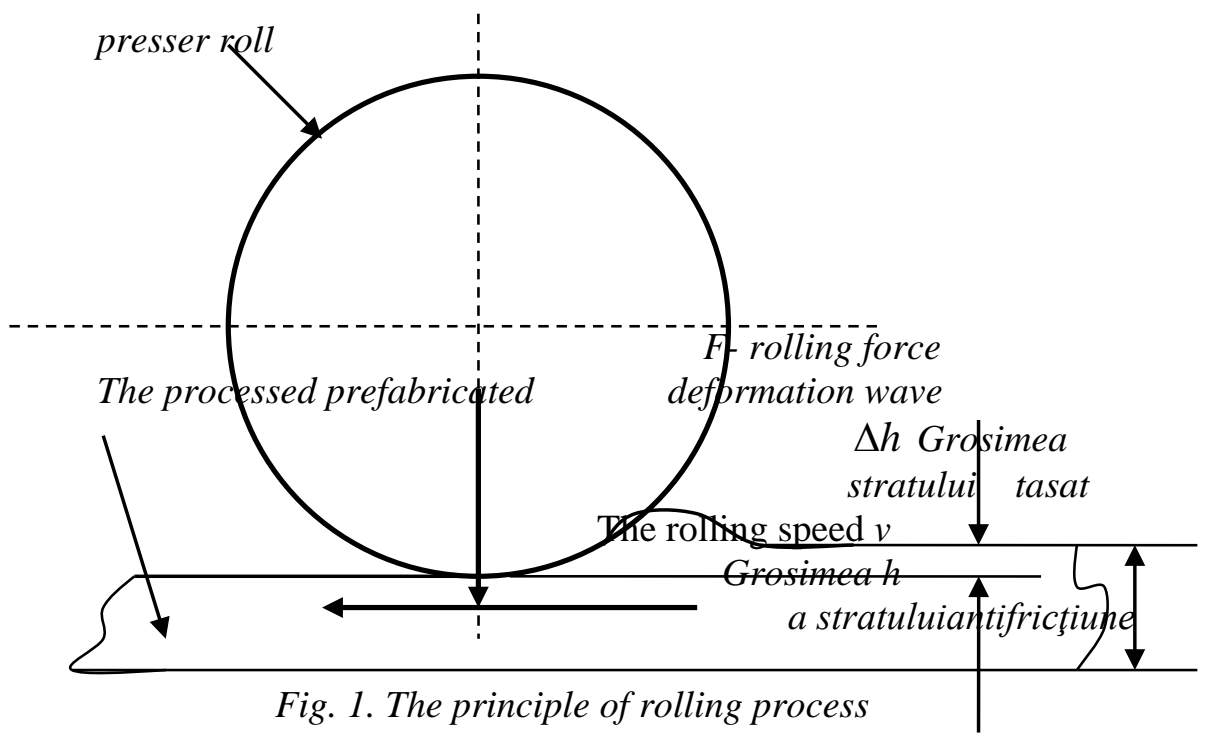

As can be seen in the $1^{\text {st }}$ figure, the process is very simple. This consist in tracing of the used prefabricated, under the presser roll action driven by a constant rolling force $F$, while the prefabricatedit's moving with the rolling speed $\mathrm{V}$, along with the mobile mass that is fastened. The presser roll can rotate freely with the peripheral speed equal with the prefabricator's speed. After the contact between the presser roll,

DOI: 10.21279/1454-864X-16-I1-032

(C) 2015. This work is licensed under the Creative Commons Attribution-Noncommercial-Share Alike 4.0 License. auctioned by force $F$ and the prefabricated, which moves with the speed $\mathrm{V}$, because of the plasticity properties, characteristic anti-friction materials, the soft layer is traced with $\Delta h$. The roller surface, hard, smooth and accurately processed will mark on anti-friction material surface, through plastical deformation at cold.

The technological parametres chosedn for study are: 
"Mircea cel Batran" Naval Academy Scientific Bulletin, Volume XIX - 2016 - Issue 1

Published by "Mircea cel Batran" Naval Academy Press, Constanta, Romania /I The journal is indexed in: PROQUEST / DOAJ / DRJI / JOURNAL INDEX / I2OR / SCIENCE LIBRARY INDEX / Google Scholar / Crossref /

Academic Keys / ROAD Open Access / OAJI / Academic Resources / Scientific Indexing Services / SCIPIO

- $\quad$ F- The rolling force

- $\quad \mathrm{N}$ - The number of passes

- $\quad$ The lack of lubrication of the roller contact with the prefabricator

- The anti-friction material and the way of submission

Besides these parametres, the processing result can be influenced by other sizes like: the rolling force, wich is equal with the speed of movement of the device's mass, the roughness of the presser rolland it's toughness, the device's rigidity and the accuracy of the relative position between the axis of the roll and the mobile mass's plan, the constant task and of the rolling speed, the thickness of the anti-friction material layer $h$, etc. The values of tecnological parametres of the FINPLAST process, used for the study samples are given in Annex, table 1.
The description of theused device for the achievement of the study samples

For study were made rectangular steel banks OL 37, plated by plastical deformation with antifriction alloy AISn10, prefabricatedused in the building S.C. "Rulmentul" S. A. from Brasov, in the series production for the camps achievement with sliding necessary for romanian industry like those for export.

To achieve the study samples the author designed and achieved a simple device adaptable on a universal lathe $\mathrm{SN}$, able to achieve the processing conditions through rolling, at a price almost neglijable.

The solution is given in the 1st picture. The presser roll, the processing tool of the device and it's mounting bracket represent a tipper witht rolles from camshaft of an engine. The whole device is fixed through a rotation bearing on a lathed shaft in the lathe. The rolling force is achieved with a lever arm (in 1st Picture.).

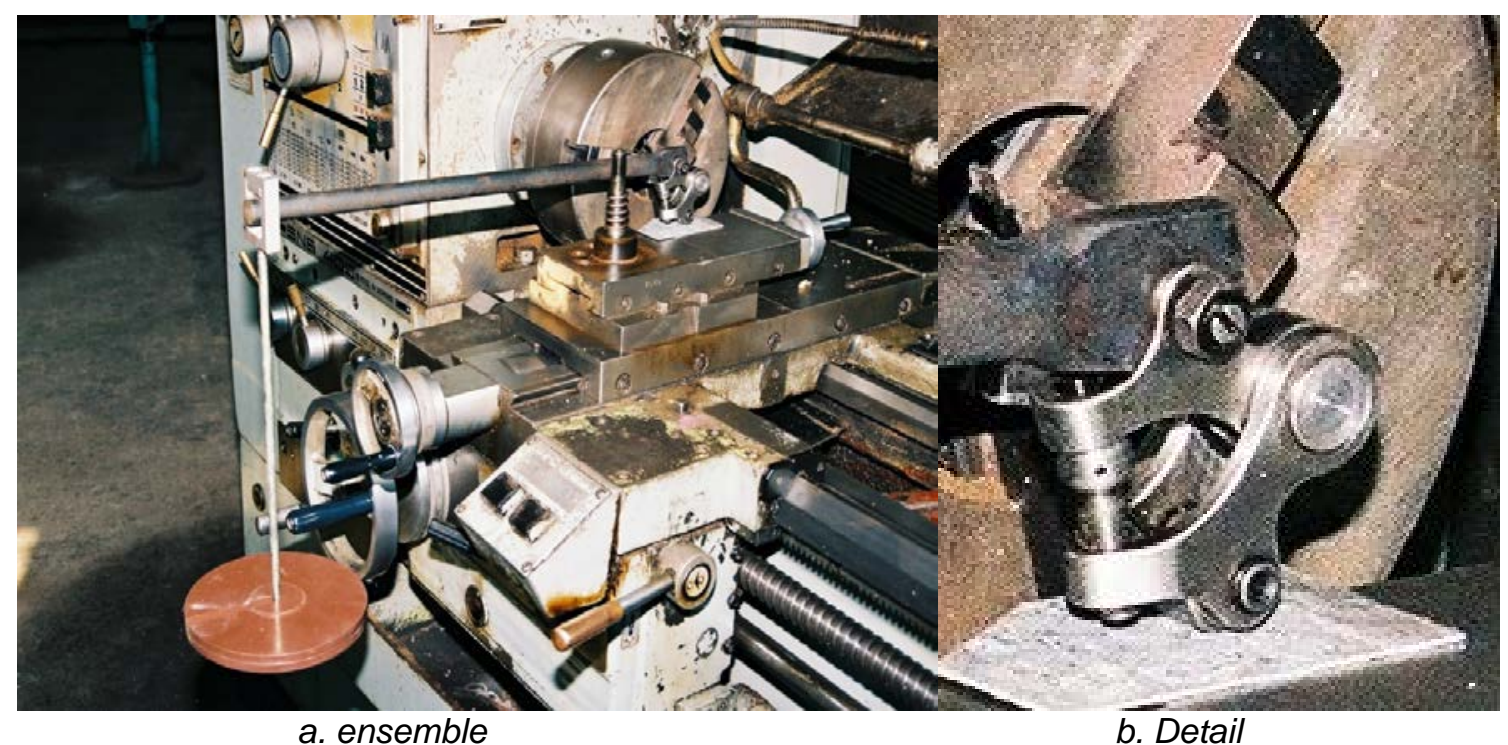

Foto 1.The device used for making the samples

The shock attempt of the achieved samples

The use of shock attempt

A first argument, for the achieve of these determinations is motivated by the fact that are a lot of bearings which in time of the operation it works on shock attempt (the internal combustion engine's bearings, of compressors with pistons, etc), this request beeing the most destructive, for every bearing. We considered useful and more accurate determination of shock behaviour, compared to the determinations of microhardness of anti-friction material, concidering the properties and the plaque OL37 thickness and the dimensionsand the properties of anti-friction layer, at the impact with the penetrator of the device for determining hardness. The error may be the main cause of the small layer of anti-friction material, in this case can become essential the effects of the suport plaque. For analysis I took into consideration the carrying out some determinations for a comparative analysis of the results. Because the impact body doesn't penetrate the layer of anti-friction material, the motherboard intake is approximately constant for all samples used. Also, because the shock attempt involves unloading in a very short time a kinetic energy, makes crucial the plastic deformation of the anti-friction layer, before being modified plastic base plaque. 
"Mircea cel Batran" Naval Academy Scientific Bulletin, Volume XIX - 2016 - Issue 1

Published by "Mircea cel Batran" Naval Academy Press, Constanta, Romania // The journal is indexed in: PROQUEST / DOAJ / DRJI / JOURNAL INDEX / I2OR / SCIENCE LIBRARY INDEX / Google Scholar / Crossref /

Academic Keys / ROAD Open Access / OAJI / Academic Resources / Scientific Indexing Services / SCIPIO

For objective results, at the shock attempt i will use a cylindrical body impactwider than the samples width, so all prints will have the same length. We should consider that a larger width print shows a higher plasticity and toughness, and a lower hardness of the lower layer and vice versa.

Due to the mechanical characteristics of the antifriction materials, lower than those of the motherboard from OL37, state of stress and strain will affect mainly in anti-friction layer.

As an answer, the anti-friction alloy will supress sideways, generating aspatial of tension state. This involves vertical deformation by tracing of the layer and the horizontal, by lateral repression.

So, the layer in the vicinity of the contact surface of anti-friction layer with the impact body, have opposite horizontal displacements, generated by forming of the deformation wave.

The description of the process

The determination is to achieve contact between a body impact, found in freefall, which strikes with a certain speed the surface of studied samples. The impact body may have shapes and sizes related to the material under test and the impact force which is used. To test some concrete machine parts, at which we know very well the forces that will be subject during operation, the impact force can simulate on the stand. This can be adjusted by bodyimpact mass and through the height from which it is launched. By the same parameters can get different impact speeds.
For the most accurate reading of the size width of fingreprints is used the lunette from the device for determining the hardness. It is able to measure the characteristic dimension of the fingerprint left on the impact body with an accuracy of one hundredth of a millimeter. Depending on the shape and size of the fingerprint it sets the value / values to be measured. Comparative determinations can be made or by comparison with samples or with other surfaces considered comparision element.

\section{The description of the stand for the shock} attempt

For conceiving stand of shock attempt, as universal as possible, we have considered several issues.Thus, it is necessar that thestand to be able to ensure the reproducibility of measurements for any number of tests.

For this, the stand must enable fine adjusting of height from which tha shock mass falls, and the influence of the operator who launches the impact body, be as low, if it can be null. In order to achieve a wide range of measurements, this should allow the use of a wide range of corps and contact surfaces with studied samples, in order to correlate body and the optimal area depending on the quality of thestudied materials

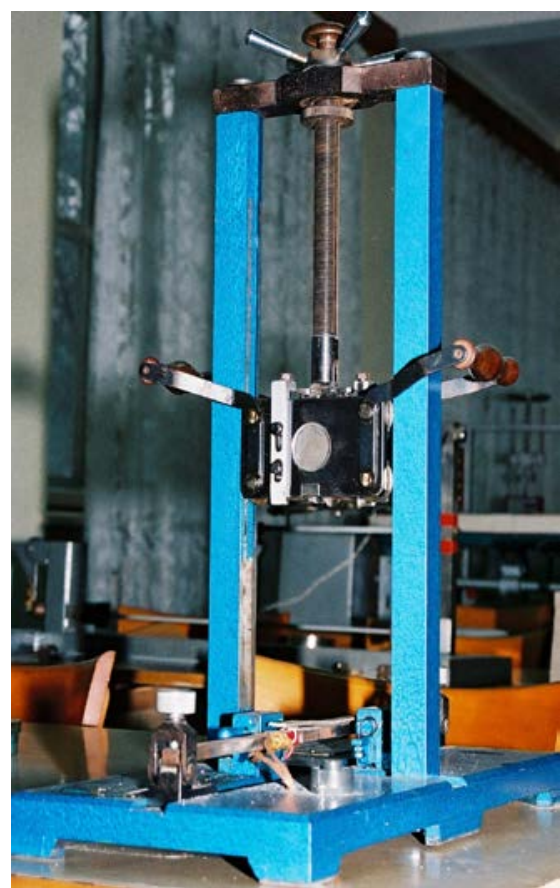

Foto 2. The stand for determing the behavior at impact

The good plasticity, very small thickness of antifriction layer which is placed on the steel base, determined me to find a solution that would increase the time of impact, to achieve the highest 


\section{"Mircea cel Batran" Naval Academy Scientific Bulletin, Volume XIX - 2016 - Issue 1 \\ Published by "Mircea cel Batran" Naval Academy Press, Constanta, Romania /I The journal is indexed in: PROQUEST / DOAJ / DRJI / JOURNAL INDEX / I2OR / SCIENCE LIBRARY INDEX / Google Scholar / Crossref / \\ Academic Keys / ROAD Open Access / OAJI / Academic Resources / Scientific Indexing Services / SCIPIO}

share of energy consumption in deformation the anti-friction layer, reducing as much as possible the energy consumption for plastical deformations of the support plaque.

For this purpose, I considered necessary design a mounting bracket of elastic study samples, adjustable according to the needs. Because the elastic deformation of the support, the impact time grows so that the anti-friction layer to have the necessary time for deformation. This mitigation of the shock occurs during operationg with shock of the bearings, by extruding the film of the lubricant. The achieving of these requirements materialized in the design of the stand according to foto 1 . According to the foto it can be seen that they chose for the impact of a mass impact solution suspended at a predetermined height $h$, which is falling vertically guided by two parallel columns.

The ram, which represents the impact mass, is a complex subassembly fulfilling several functions. It is guided on the two columns of blue colour, by 4 profiled roller bearing by means of needle bearings, such as frictional losses to be minimal. For lifting the ram it is provided with two lateral handles, conveniently placed. The suspension of the ram at the clamp screw, vertically adjustable, is carried out by means of two levers claw (foto 1.).

For the avoidance of the set position, secure with a check nut placed just under the crossbar support. For easy turning of the screw in the threaded nut bar, his head is provided with four handles realizing a convenient way of handling, as it can be seen in the foto. On top of this handling roll can be observed a brown fungus, which by means of a rod passing through a hole over the entire length of the screw, command when it is pressed to open the fixing claws of the impact mass of the, the operator influence during this operation is minimal.

In order to achieve the impact with different sizes of the body impact surface, the ram it is provided centrally in the bottom with a place where can be fixed different impact bodies. For tests the impact body had the shape of a cylinder, with the diameter of $32 \mathrm{~mm}$, located with the axis of rotation in the plane of the guide columns. These dimensions have been established through some preliminary testing which determined the size in which the support plaque deformations are minimal, and the value of fingreprints presents noticeable dimensional differences from one sample to another.

To achieve an elastic contact, the prefabricated under test, is fixed on an elastic bar, of rectangular cross-section $12 \times 6 \mathrm{~mm}$ and the maximum length between supports fixing of $400 \mathrm{~mm}$, placed transversely in the path of the impact mass. Fixing the bar is made on two

DOI: 10.21279/1454-864X-16-I1-032

(C) 2015. This work is licensed under the Creative Commons Attribution-Noncommercial-Share Alike 4.0 License. supports bar-type knives, allowing the free rotation of the end of the bar during deformation. The bearings are fixed of the support using butterfly tightening screws. The two supports for fixing the elastic bar may approach 10 to $10 \mathrm{~mm}$. Because of the symmetry required to obtain the most accurate results, the distance between bearings will modify with $20 \mathrm{~mm}$, thus obtaining, different elastic characteristics of the bracket. The minimum size between brackets is of $200 \mathrm{~mm}$.

The bar has mounted on it at the bottom a strain gauge, that the author has expanded the possibilities of measurement of the device. By coupling it to a system with strain gauge bridge, can accurately determine the elastic deformation value. By comparison, it can be seen which materials are tougher, which are more elastic or plastic. By coupling the bridge to a computer interface is carried out the possibility of active measurement which can give more accurate information about shock behavior of the studied samples, in this case the shock influence of antifriction material layer on the dynamics of deformation bar.

To avoid repeating the blow bar at the same fall of the ram, I designed a mechanical restraint system, using throwing the ram vertically by the elastic bar after the ram reached the lowest point and the total deformation energy is consumed.

The device consists of two retainers' devices with a retainer horizontal which is eliminated by one coil spring from the slots in the ram way after it is raised by the elastic bar. The springs are prestressing manual, and when the ram got on the end position expansion command is given by one command bar of duralumin.

Thus, after elastic support bar whereon there are fastened the study samples, become completely deformed, the two command bars of duralumin command the barriers of retaining of the stopper. Once the ram is thrown up vertically, retention stoppers do not allow it the second contact with the sample. After every attempt, the retention stoppers are retracted manually arming the drive springs. The restraint devices of blue color are place side, away and cross of the elastic bar, on each part of the ram. In pic 1.b., can be seen the manual retracting handle, of the stopper of the device.

Fixing study samples is made with elastic rubber rings used to bind banknotes. This solution eliminates fixing any additional deformations during the impact, allowing self-centering of specimens on the elastic bar. Due to very small forces from links, it's not influenced the way that the bar is deformed.

If it is desired firmly fixing of the studied sample, the elastic bar is replaced with a plaque having a thickness equal to the height of the point of impact 
"Mircea cel Batran" Naval Academy Scientific Bulletin, Volume XIX - 2016 - Issue 1

Published by "Mircea cel Batran" Naval Academy Press, Constanta, Romania // The journal is indexed in: PROQUEST / DOAJ / DRJI / JOURNAL INDEX / I2OR / SCIENCE LIBRARY INDEX / Google Scholar / Crossref /

Academic Keys / ROAD Open Access / OAJI / Academic Resources / Scientific Indexing Services / SCIPIO

of the elastic bar. The device was achieved within the workshops in "Mircea cel Batran" Naval Academy, using many parts scrapped.

The main features of the device are: minimum height of fall $\mathrm{h}$ is $145 \mathrm{~mm}$, it can be infinitely adjusted up to $300 \mathrm{~mm}$, and the mass of the ram is $1.72 \mathrm{~kg}$.

Making experimental measurements.

For the experimental measurements It was used an impact body with a cylindrical shape with a radius $R=32 \mathrm{~mm}$. The height of tests were carried out, was of $155 \mathrm{~mm}$. The total weight of the mass of impact was $1,72 \mathrm{Kg}$.

Fingerprints are roughly rectangular shape. Samples of work of author's determinations consist of strips of width of $12 \mathrm{~mm}$ cut perpendicular to the direction of rolling. For an easier identification of the achieved samples they were coded according to Table 1.

For this was cut transversely from the plaque with samples a tape containing the 6 samples with codes from 2.1, and 2.6. Technological parameter values used are listed in Table 1 with the fingerprints values read on studied samples. In addition to the 6 samples were also subjected to the test a sample that has not been finished by the process FINPLAST, considered as a standard sample for comparison. Elastic bar is provided with a sign indicates the point of contact with the impact body. At this point is fitted the lane with the corresponding position of the studied sample from 2.1. of $155 \mathrm{~mm}$

Adjust and set the impact mass at height

\section{- $\quad$ Retract the ram restraint devices}

- $\quad$ Remove the elastic bar from bearings and secure it with elastic rubber rings each sample

- Fit the bar on bearings after which pressing the command fungus, the impact mass descends, strikes the sample and it's going down deforming the elastic bar.

- Unlocks impact mass. When the ram reaches the finish line the command bars triggers the retention obstacles of the mechanism. The elastic bar throws up the impact mass after which retaining levers prevents a second impact with the sample.

This operation is repeated for each sample, to perform all measurements, according to the table with experimental results.

The technological parameters of these samples are given in Table 1.

Experimental results

Impact fingerprints obtained by the method described above are read with a lunette with micrometer from Brinell machine. The following are shown in Table 1, the fingerprint data readings along with parameter values used to achieve samples.

Table 1. The mean values of fingreprints

\begin{tabular}{|l|l|l|l|l|}
\hline $\begin{array}{l}\text { Identifi } \\
\text { cated } \\
\text { cod }\end{array}$ & $\begin{array}{l}\text { Rolling } \\
\text { force F } \\
\text { [daN] }\end{array}$ & $\begin{array}{l}n-\text { nr. } \\
\text { of } \\
\text { pasez }\end{array}$ & $\begin{array}{l}\text { Lubri } \\
\text { Ficted } \\
?\end{array}$ & $\begin{array}{l}\text { Dimen } \\
\text { sion } \\
\text { of B } \\
1,93\end{array}$ \\
\hline Etalon & & & No & 1,81 \\
\hline 2.1 & 77,5 & 1 & No & 1,79 \\
\hline 2.2. & 248,2 & 1 & No & 1,73 \\
\hline 2.3. & 248,2 & 2 & No & 1,69 \\
\hline 2.4. & 248,2 & 3 & yes & 1,73 \\
\hline 2.5. & 328,5 & 1 & yes & 1,70 \\
\hline 2.6. & 328,5 & 2 &
\end{tabular}

For a simple explanation of the influence of parameters of accomplishment of finish with the FINPLAST process, of anti-friction layer are shown in Fig.1 and Fig.2 the graphs of variation of the width $B$, of measured fingerprint, of samples. 
"Mircea cel Batran" Naval Academy Scientific Bulletin, Volume XIX - 2016 - Issue 1 Published by "Mircea cel Batran" Naval Academy Press, Constanta, Romania // The journal is indexed in: PROQUEST / DOAJ / DRJI / JOURNAL INDEX / I2OR / SCIENCE LIBRARY INDEX / Google Scholar / Crossref I Academic Keys / ROAD Open Access / OAJI / Academic Resources / Scientific Indexing Services / SCIPIO

\section{The graphs of variation of the width $B$, by rolling force}

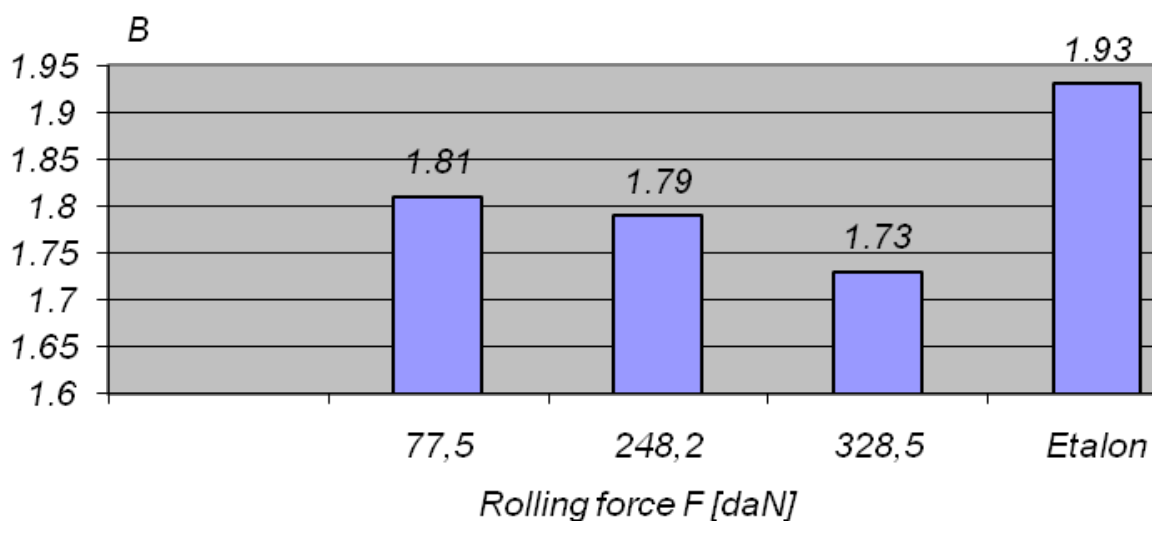

Fig.1.

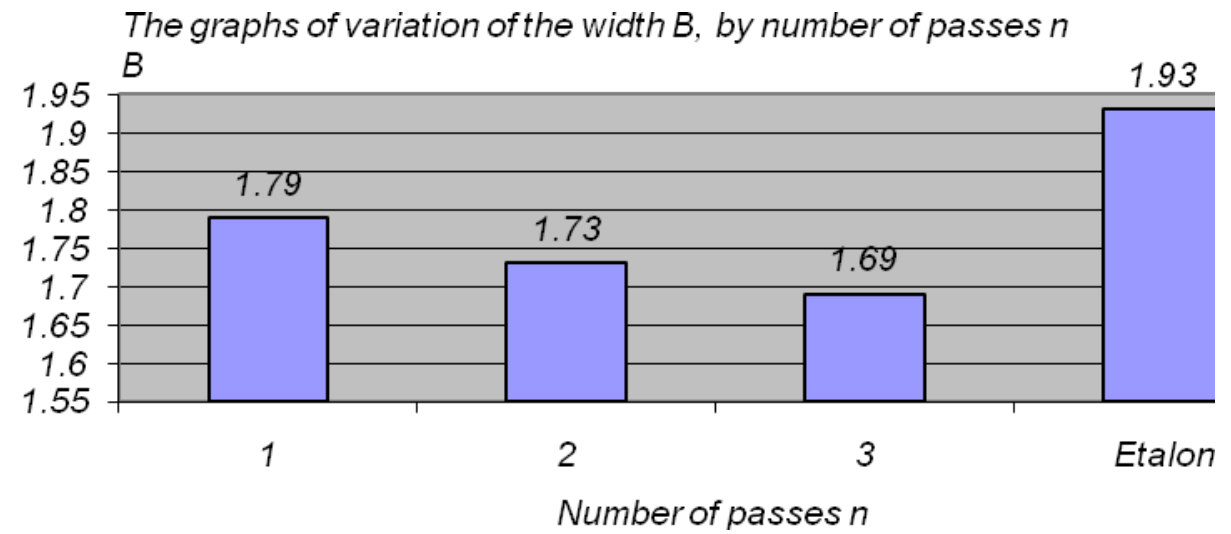

Fig. 2.

\section{CONCLUSIONS}

- The obtained results, through fine differences obtained shows that the uses of the shock attempt of the anti-friction layer can be useful, even recommended.

- It is noted the significant change of the behavior at impact of anti-friction layer compared to that which was not finished.

- Increasing the rolling force $F$, and the number of passes $n$, produce a change of mechanical qualities of the layer shown by the fingerprints measured values;

- Achieving a certain routines with experimental determinations of footprint at shock could lead to the establishment in time of some numerical absolute values that can be used from the design stage;

- These determinations in conjunction with experimental evaluations with bearing components given into exploitation, measured after different periods of exploitation of these bearings finished by the FIMPLAST process, could be particularly useful in future.

- In assessing the behavior at shock, we should consider that a bigger width B, means a smaller dimensional stability in time and therefore an increase in functional game and vice versa;

- A smaller width B shows a better dimensional stability and so a reduction in functional game with less settlement;

- A smaller width B instead shows a reduction in capacity of adaptability of bearing in any deviation of position and / or shape, which is a decline in overall quality and performance of operation and exploitation. 
"Mircea cel Batran" Naval Academy Scientific Bulletin, Volume XIX - 2016 - Issue 1

Published by "Mircea cel Batran" Naval Academy Press, Constanta, Romania // The journal is indexed in: PROQUEST / DOAJ / DRJI / JOURNAL INDEX / I2OR / SCIENCE LIBRARY INDEX / Google Scholar / Crossref / Academic Keys / ROAD Open Access / OAJI / Academic Resources / Scientific Indexing Services / SCIPIO

- The areas in the vicinity of the contact surface of the anti-friction layer with the impact body are subjected on a state of significant stress and strain. This involves so much deformation in vertical plan, by settlement and so much in horizontal plan by discharging the ant frictional material. Because of the symmetry, in horizontal plan take place opposite movements, generated by forming the deformation wave.

- The dimension of the contact fingerprint and the deformation wave are directly dependent on the thickness of anti-frictional layer

- Because the shock attempt involves unloading in a very short time a kinetic energy, the bigger differences in the mechanical characteristics of the two materials makes decisive the plastic deformation of the anti-friction layer, before the support plaque being plastically modified.

- It should be considered that the impact body doesn't penetrate anti-friction layer motherboard intake is approximately constant for any of the studied samples.

\section{BIBLIOGRAPHY}

[1] Attila Palfalvi, Incercarea materialelor, Volumul I, Incercări distructive ale metalelor, Editura Tehnica, 1982

[2] Nou procedeu de finisare a lagărelor cu alunecare ,FINPLAST”, editura Printech 2004, Bucureşti, 